\title{
Dipyridamole induces the phosphorylation of CREB to promote cancer cell proliferation
}

\author{
LINA ABDELGHANY ${ }^{1-3}$, NAGEH EL-MAHDY ${ }^{3}$, TSUYOSHI KAWABATA $^{1,2}$, \\ SHINJI GOTO ${ }^{1,2}$ and TAO-SHENG LI ${ }^{1,2}$ \\ ${ }^{1}$ Department of Stem Cell Biology, Atomic Bomb Disease Institute, Nagasaki University; \\ ${ }^{2}$ Department of Stem Cell Biology, Nagasaki University Graduate School of Biomedical Sciences, Nagasaki 852-8523, Japan; \\ ${ }^{3}$ Department of Pharmacology and Toxicology, Faculty of Pharmacy, Tanta University, Tanta 31527, Egypt
}

Received February 28, 2020; Accepted October 30, 2020

DOI: $10.3892 / 01.2021 .12512$

\begin{abstract}
Dipyridamole, a traditional anti-platelet drug, has been reported to inhibit the proliferation of cancer cells. The present study aimed to investigate the possibility of dipyridamole as an adjuvant of chemotherapy by enhancing the cytotoxicity of an anti-cancer drug. The cytotoxicity of colorectal cancer cells (HCT-8), CD133 ${ }^{+} / \mathrm{CD}_{4} 4^{+}$stem-like subpopulation of HCT-8 cells and lymphoma cells (U937) to dipyridamole and/or doxorubicin was evaluated using MTT proliferation and colony forming assays. The expression levels of phosphorylated cAMP-regulatory element-binding protein (pCREB) and poly(ADP-ribose) polymerase-1 (PARP-1) in cells were analyzed via western blotting and immunofluorescence. The present study reported controversial data regarding the anti-cancer effect of dipyridamole. Dipyridamole increased, rather than inhibited, the proliferation of HCT-8 and U937 cells in a dose-dependent manner. Furthermore, it was found that dipyridamole significantly increased the expression levels of pCREB and PARP-1. However, the combined usage of dipyridamole significantly enhanced the cytotoxicity of doxorubicin to HCT-8 cells at particular doses. Based on the current findings, dipyridamole likely induces the phosphorylation of CREB to promote the proliferation of cancer cells, but may enhance the cytotoxicity of anti-cancer drugs at particular doses.
\end{abstract}

\section{Introduction}

Dipyridamole, a traditional anti-platelet agent, is an inhibitor of phosphodiesterase enzyme 3 (PDE3) and PDE5, which results in

Correspondence to: Dr Tao-Sheng Li, Department of Stem Cell Biology, Atomic Bomb Disease Institute, Nagasaki University, 1-12-4 Sakamoto, Nagasaki 852-8523, Japan

E-mail: litaoshe@nagasaki-u.ac.jp

Key words: dipyridamole, doxorubicin, human colorectal cancer, lymphoma, stem cells the accumulation of cyclic adenosine monophosphate (cAMP) and cyclic guanosine monophosphate (cGMP) (1), consequently increasing protein kinase A (PKA) and PKG, respectively (2). Previous studies have reported that dipyridamole enhances the cytotoxicity of anti-tumor drugs, such as 5-flurouracil (3), cisplatin (4) and methotrexate $(5,6)$, as well as preventing tumor progression (7) and decreasing the proliferative activity of cancer cells $(2,8)$. Although dipyridamole has been reported to inhibit the re-uptake of adenosine and downregulate cyclin D1 and c-Myc levels (7), the precise role and the relevant mechanism of dipyridamole in regulating the proliferation of cancer cells is yet to be elucidated. Moreover, there is no consensus on the anti-cancer effect of dipyridamole.

Complex signaling pathways are known to mediate the proliferation, survival and therapeutic resistance of cancer cells (9). Of which, cAMP-regulatory element-binding protein (CREB) has been demonstrated to serve a critical role in both hematologic and non-hematologic malignancies $(10,11)$ via the phosphorylation of various kinases, such as Akt and PKA $(12,13)$. Moreover, the cAMP/PKA axis has been demonstrated to regulate poly(ADP-ribose) polymerase-1 (PARP-1) (14), which is known to serve an important role not only in DNA repair (15), but also the development and progression of malignant tumors $(16,17)$. As dipyridamole may induce the accumulation of cAMP and cGMP to support the survival and proliferation of cells, the precise role of dipyridamole on the proliferation of cancer cells requires further investigation.

Doxorubicin is a widely prescribed chemotherapeutic drug, but its use in high doses is limited due to serious side effects, such as myelotoxicity and cardiotoxicity (18). Considering the favorable safety profile of dipyridamole, it will be beneficial to use dipyridamole as adjuvant drug for enhancing the sensitivity of cancer cells to doxorubicin. Therefore, the present study aimed to investigate the anti-cancer effect of dipyridamole in combination with doxorubicin.

Using human colorectal cancer cells (HCT-8), $\mathrm{CD} 133^{+} / \mathrm{CD} 44^{+}$stem-like subpopulation of HCT-8 cells and human monocyte histiocytic lymphoma cells (U937), it was identified that dipyridamole increased, rather than inhibited, the proliferation of HCT-8 and U937 cells in a dose-dependent manner. However, the cytotoxicity of doxorubicin was 
enhanced by the combined usage of dipyridamole at particular doses.

\section{Materials and methods}

Cell culture. Human colorectal cancer cells (HCT-8), CD133 $/$ CD $44^{+}$stem-like subpopulation of HCT- 8 cells and human monocyte histiocytic lymphoma cells (U937) were used for the experiments. Cells were maintained in RPMI-1640 medium (Fujifilm Wako, Inc.) supplemented with 10\% FBS (Corning, Inc.) and $1 \%$ penicillin/streptomycin (Fujifilm Wako, Inc.), at $37^{\circ} \mathrm{C}$ in a humidified atmosphere with $5 \% \mathrm{CO}_{2}$ and $95 \%$ air.

Cytotoxicity assay. Based on previous publications $(2,7,8)$, we used 0,10 and $20 \mu \mathrm{M}$ dipyridamole in this study. For doxorubicin, we used the same dose of $0,1.0$ and $3.0 \mu \mathrm{M}$ for HCT- 8 cells as our previous study (19). However, the cytotoxicity of doxorubicin largely vary among cancer cell lines (20). As cytotoxicity of doxorubicin to U937 cells was highly indicated even at dose of $0.5 \mu \mathrm{M}$ in our preliminary experiment, we used $0,0.1$ and $0.2 \mu \mathrm{M}$ doxorubicin for U937 cells in this study. Cytotoxicity assay was performed using the Cell Proliferation Kit I (MTT) according to the manufacturer's protocol (Roche Diagnostics). Briefly, cells were seeded in 96-well culture plates $\left(5 \times 10^{3}\right.$ cells $/$ well $)$ and cultured overnight. Cells were then treated with various concentrations of doxorubicin (Fujifilm Wako, Inc.) and dipyridamole (Sigma-Aldrich; Merck KGaA). At $24 \mathrm{~h}$ after treatment, MTT was added and incubated for another $4 \mathrm{~h}$. The formation of formazan from MTT was stopped by adding solubilization solution, and the absorbance of formazan was measured at $570 \mathrm{~nm}$ using a microplate reader (iMark $^{\mathrm{TM}}$ Microplate Reader; Bio-Rad Laboratories, Inc.). The optical density (OD) value of cells with vehicle treatment was used as a normalization control (100\%). The combination effect was analyzed with coefficient of drug interaction $[C D I=A B /(A \times B)]$, where $A B$ is the $O D$ value ratio of the combination group and vehicle groups, $\mathrm{A}$ is the $\mathrm{OD}$ value ratio of the drug $\mathrm{A}$ and vehicle groups, and $\mathrm{B}$ is the $\mathrm{OD}$ value ratio of the drug $\mathrm{B}$ and vehicle groups. CDI value $<1$ indicates a synergistic effect, $C D I$ value $=1$ indicates an additive effect and CDI value $>1$ indicates an antagonistic effect. Optical density (OD); coefficient of drug interaction (CDI).

Colony forming assay (CFA). A CFA was performed to confirm the MTT assay data of dipyridamole in regulating the proliferation of parent and $\mathrm{CD} 133^{+} / \mathrm{CD} 44^{+}$stem-like subpopulation of HCT-8 cells. After treatment with $20 \mu \mathrm{M}$ dipyridamole for $24 \mathrm{~h}$, the cells were collected, re-cultured in 6-well culture plate (200 cells/well) and incubated for 10 days. Colonies were fixed with $4 \%$ formalin (Fujifilm Wako, Inc.) for $20 \mathrm{~min}$ and stained with $0.5 \%$ crystal violet solution for $1 \mathrm{~h}$. Colonies were counted using ImageJ 2.1.0 software (National Institutes of Health).

Western blotting. Western blotting was performed as previously described (21). Briefly, cells were lysed in Laemmli's buffer. Total proteins were separated using SDS-PAGE and were then transferred to PVDF membranes (Bio-Rad Laboratories, Inc.). After blocking, the membranes were incubated with primary antibodies against rabbit phosphorylated (p)CREB (Ser133; 1:1,000, cat. no. ab32096; Abcam), rabbit PARP-1 (1:1,000 cat. no. 9542; Cell Signaling Technology, Inc.) and mouse $\alpha$-tubulin (1:1,000, cat. no. 3873; Cell Signaling Technology, Inc.) which was followed by incubation with appropriate horseradish peroxidase-conjugated secondary antibodies against rabbit (1:2,000, cat. no. p0448; Dako Agilent Technologies) and mouse (1:2,000, cat. no. p0260; Dako Agilent Technologies). The expression was visualized using an ECL detection kit (cat. no. RPN2106; Cytiva). Images were acquired using ImageQuant LAS 4000 Mini biomolecular imager (Cytiva). Semi-quantification on the relative expression of proteins was performed using ImageJ 2.1.0 software (National Institutes of Health).

Immunofluorescence staining. Immunofluorescence staining was performed to detect the expression of pCREB. Briefly, cells were fixed with $4 \%$ formalin (Fujifilm Wako, Inc.) for $10 \mathrm{~min}$. After blocking, cells were incubated with primary antibodies against pCREB (1:100) at room temperature for $1 \mathrm{~h}$, followed by incubation with an Alexa Fluorescent 546-conjugated secondary antibody against rabbit Ig (1:500 cat. no. A11035; Invitrogen; Thermo Fisher Scientific, Inc.) at room temperature for $1 \mathrm{~h}$ in the dark. The cell nuclei were labeled with DAPI.

Statistical analysis. Data are presented as the mean \pm SEM for three independent experiments. The data were analyzed using one-way ANOVA, followed by Tukey's multiple comparison post-test. $\mathrm{P}<0.05$ was considered to indicate a statistically significant difference. All analyses were performed using GraphPad Prism 8.0 software or Excel Microsoft 365.

\section{Results}

Dipyridamole increases the proliferation of cancer cells. A MTT assay is used to evaluate the proliferation of cancer cells. The addition of dipyridamole $(0-20 \mu \mathrm{M})$ increased the proliferation of U937 cells, parent HCT-8 cells and the $\mathrm{CD} 133^{+} / \mathrm{CD}_{4} 4^{+}$stem-like subpopulation of HCT- 8 cells in a dose-dependent manner (Fig. 1A).

To further assess the data of the MTT assay, a colony forming assay was conducted for parent and $\mathrm{CD} 133^{+} / \mathrm{CD} 44^{+}$ stem-like subpopulation of HCT- 8 cells. Dipyridamole $(20 \mu \mathrm{M})$ increased the number of colonies for parent HCT-8 cells (from $748 \pm 70$ to $866 \pm 172 ; \mathrm{P}=0.33$ ) and $\mathrm{CD} 133^{+} / \mathrm{CD} 44^{+}$stem-like subpopulation of HCT-8 cells (from $761 \pm 122$ to $1106 \pm 176$; $\mathrm{P}=0.04$ ) (Fig. 1B). Based on these findings, dipyridamole may promote, but not inhibit the proliferation of cancer cells.

Dipyridamole enhances the expression levels of $p C R E B$ and PARP-1. Western blotting was performed to investigate the potential mechanism on the proliferation of cancer cells induced by dipyridamole. It was identified that the expression of pCREB in all cancer cells was increased at 30 or $60 \mathrm{~min}$ after $20 \mu \mathrm{M}$ dipyridamole treatment (Fig. 2A). The enhanced expression of pCREB was also confirmed via immunofluorescence staining (Fig. 2B). Furthermore, the expression of PARP-1 in all cancer cells was enhanced at 30 or 60 min after $20 \mu \mathrm{M}$ dipyridamole treatment (Fig. 3). 
A

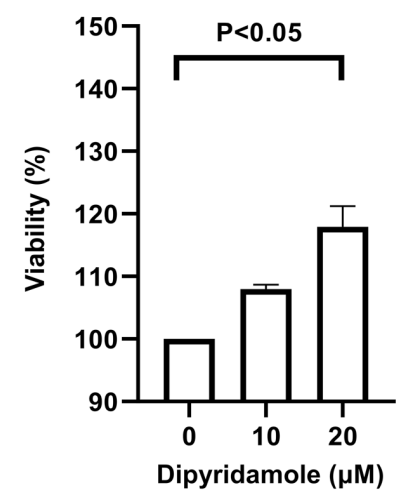

B

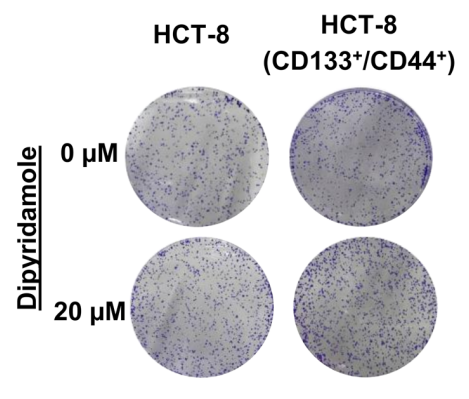

HCT-8 (CD133 $\left.{ }^{+} / \mathrm{CD}^{4} 4^{+}\right)$

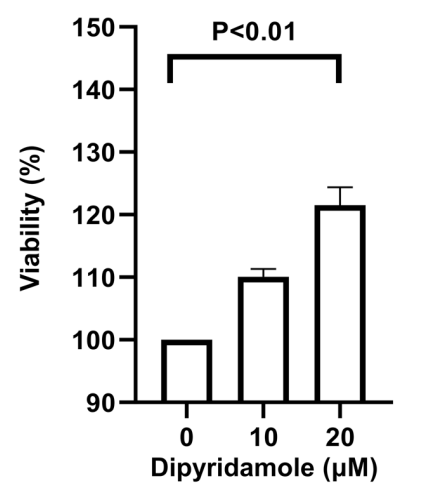

HCT-8

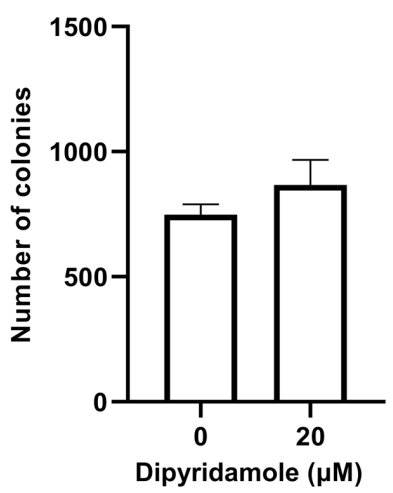

U937

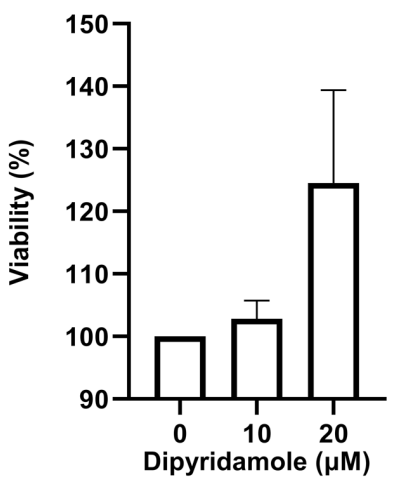

HCT-8 $\left(\mathrm{CD} 133^{+} / \mathrm{CD}^{4} 4^{+}\right)$

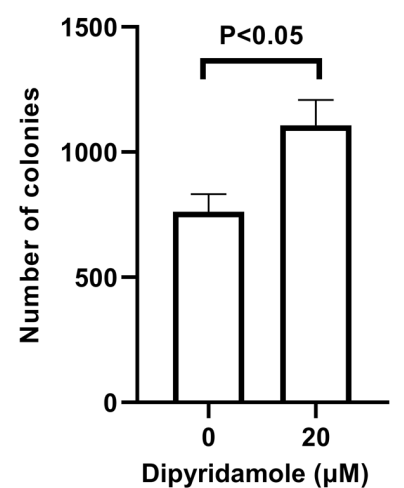

Figure 1. Proliferation of HCT- 8 cells, CD133 ${ }^{+} / \mathrm{CD} 44^{+}$stem-like subpopulation of HCT-8 cells and U937 cells. (A) MTT assay was used to assess the viability of cancer cells treated with various doses of dipyridamole. (B) Colony forming assay was used to assess the proliferation of parent and $\mathrm{CD} 133^{+} / \mathrm{CD} 44^{+}$ stem-like subpopulation of HCT-8 cells.

Cytotoxicity of doxorubicin is enhanced by dipyridamole at particular doses. To evaluate whether dipyridamole enhances the cytotoxicity of doxorubicin to cancer cells, various doses of dipyridamole were added to cancer cells in combination with doxorubicin treatment. The correct doses for both drugs were chosen according to the reported literature and preliminary experiments $(19,20)$, and the $\mathrm{IC}_{50}$ values of doxorubicin were calculated as $5.95 \mu \mathrm{M}$ for HCT- 8 cells, $10.63 \mu \mathrm{M}$ for the subpop-

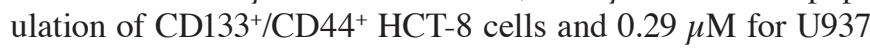
cells (Fig. S1). As indicated by the quantitative data of the MTT assay (Fig. 4; Table SI), dipyridamole significantly enhanced the sensitivity of cancer cells to doxorubicin, but only at a particular dose (10 $\mu \mathrm{M}$ dipyridamole with $3 \mu \mathrm{M}$ doxorubicin for HCT-8 cells). However, dipyridamole at any of the other doses failed to demonstrate a significant enhancement of doxorubicin cytotoxicity to these cancer cells (Fig. 4; Tables SII and SIII).

\section{Discussion}

Dipyridamole, one of the most commonly used anti-platelet agents, is also often prescribed to some patients with cancer. Previous studies have reported that dipyridamole sensitizes cancer cells to chemotherapeutic agents (2-7). Although dipyridamole exerts an anti-proliferative effect on breast and prostate cancer cells $(2,7)$, the anti-cancer benefit of dipyridamole to patients with cancer is yet to be fully elucidated.

The present study aimed to investigate the precise role on the anti-cancer benefit of dipyridamole. In contrast to previous studies (2-7), the present results suggested that dipyridamole increased the proliferation of parent HCT- 8 cells, CD133 $/ \mathrm{CD}^{+} 4^{+}$stem-like subpopulation of HCT- 8 cells and U937 cells in a dose-dependent manner. Although the current study neither evaluated cAMP or cGMP levels, nor the activation of cAMP/PKA or cGMP/PKG signaling pathways, the increased cell proliferation induced by dipyridamole could be explained as follows: PDE3 and PDE5 are extensively expressed in healthy tissue cells (22), and upregulated in multiple cancer cells, including HCT-8 and U937 $(13,23)$. As an inhibitor of PDE3 and PDE5, dipyridamole usually induces the accumulation of cAMP and cGMP in cells (1). cAMP and cGMP are generally known to activate PKA and PKG, respectively, which induces the phosphorylation of CREB $(13,24)$ and pCREB regulates the expression of several genes involved in the metabolism, proliferation, differentiation and survival of cells (12). Thus, we speculate that the increased cellular levels of cAMP and cGMP contribute to the small beneficial effect of dipyridamole on the cell survival/proliferation (up to around $20 \%$ by MTT assay). Moreover, the present results indicated that dipyridamole increased the expression of pCREB in U937 lymphoma cells, parent HCT- 8 colorectal cancer cells and the $\mathrm{CD} 133^{+} / \mathrm{CD}_{4} 4^{+}$ stem-like subpopulation from HCT-8 cells. Although we have not yet investigated, it is possible that other PDE3 and PDE5 inhibitors may also beneficial of cell proliferation. The current findings suggested that dipyridamole enhanced the expression of PARP-1, which known to support the survival 

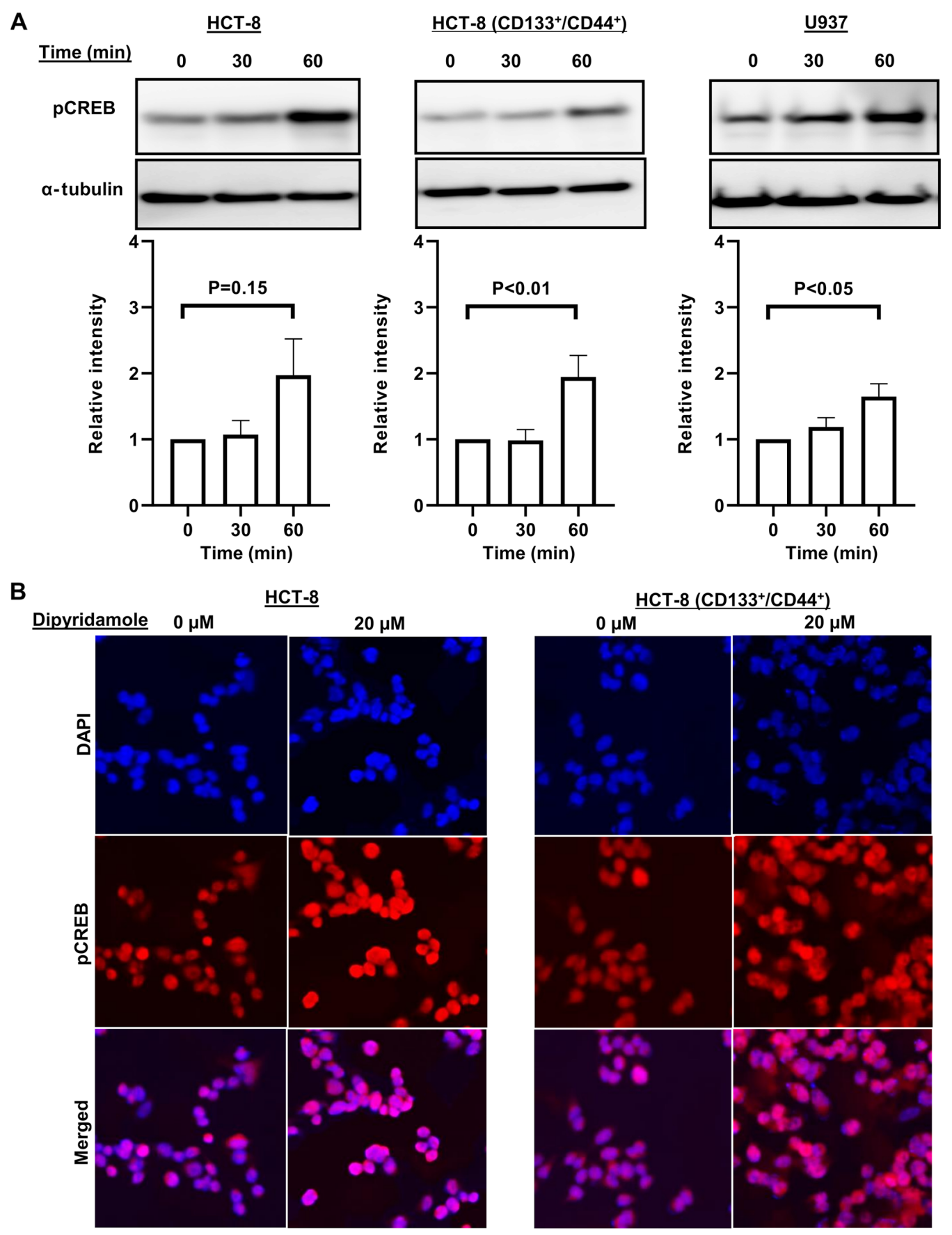

Figure 2. Expression of pCREB in HCT-8 cells, CD133+/CD44 ${ }^{+}$stem-like subpopulation of HCT-8 cells and U937 cells. (A) Western blot analysis of the expression of pCREB in cells treated with $20 \mu \mathrm{M}$ dipyridamole. (B) Immunofluorescence staining of the expression of pCREB in cells 60 min after treatment with $20 \mu \mathrm{M}$ dipyridamole (magnification, $\mathrm{x} 60$ ). $\mathrm{pCREB}$, phosphorylated cAMP-regulatory element-binding protein.

and proliferation of cancer cells. Thus, dipyridamole may promote, rather than inhibit, the survival and proliferation of cells, but further details of the relevant mechanisms require additional investigations.

Doxorubicin is commonly used for in vitro experiments and clinics $(21,25-30)$. However, doxorubicin is rarely prescribed to patients with colorectal cancer as the expression of P-glycoprotein in colorectal cancer contributes to doxorubicin resistance $(23,26)$. As dipyridamole has been reported to inhibit P-glycoprotein (28), synergistic effects of dipyridamole and doxorubicin are expected for patients with colon cancer. The present study investigated whether dipyridamole could enhance the cytotoxicity of doxorubicin to these cancer cells. Interestingly, the cytotoxicity of doxorubicin was significantly enhanced by dipyridamole, only to HCT-8 cells in particular dose. A previous study also reported that dipyridamole alone or in combination with methotrexate failed to increase the cytotoxicity in leukemia cells (29). In fact, the small compound of dipyridamole not only inhibits PDE3 and PDE5, but also regulates multiple cell signaling pathways $(2,7)$. Therefore, the anti-cancer effect of dipyridamole used alone or with doxorubicin may largely depend on the cell types and other conditions (30). Further basic experiments using additional cancer cell lines, as well as clinical 


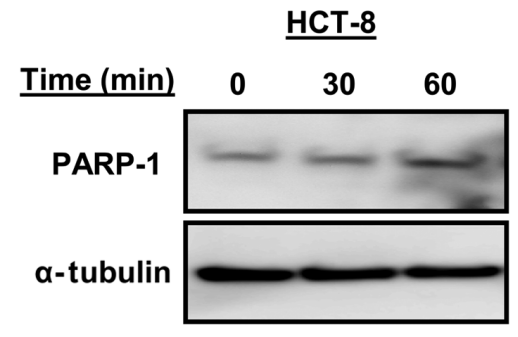

HCT-8 (CD133 $\left.{ }^{+} / \mathrm{CD}^{-} 4^{+}\right)$
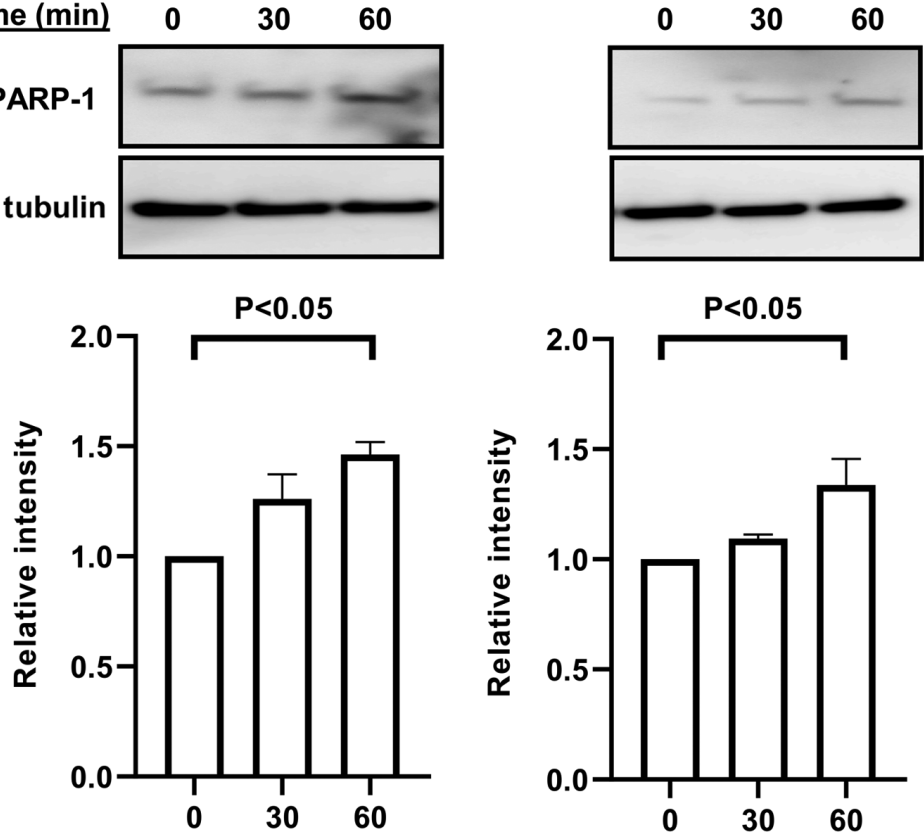

Time $(\min )$

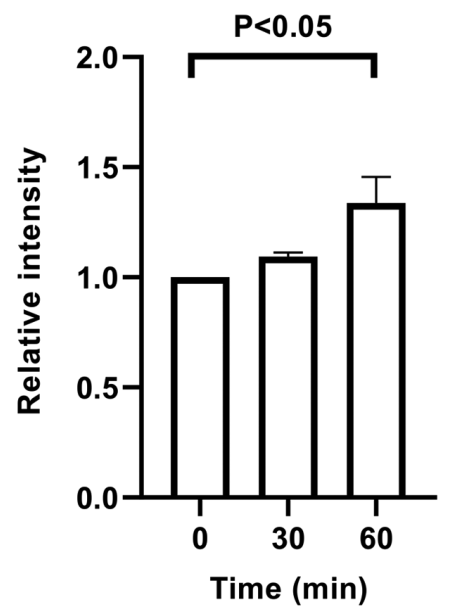

Figure 3. Expression of PARP-1 in HCT- 8 cells, CD133 $/$ CD44 $4^{+}$stem-like subpopulation of HCT-8 cells and U937 cells treated with $20 \mu \mathrm{M}$ dipyridamole. Representative images and semi-quantitative data of western blot analysis. PARP-1, poly(ADP-ribose) polymerase-1.

A
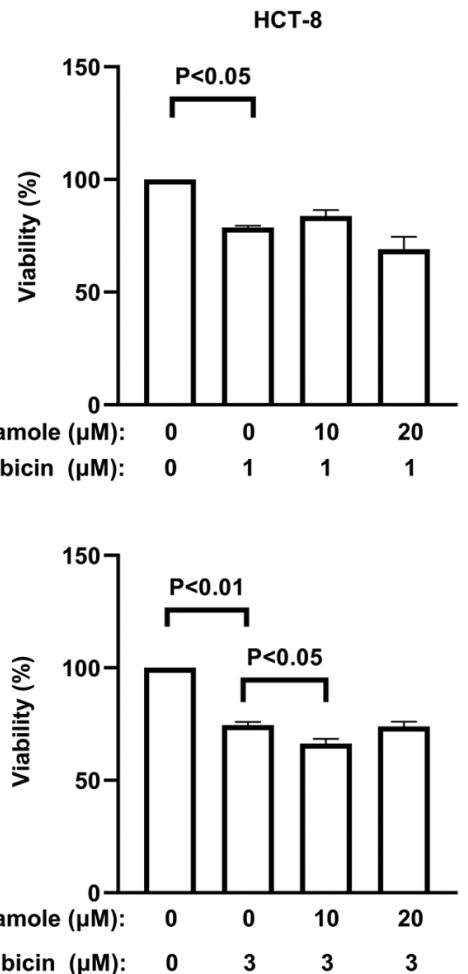

B
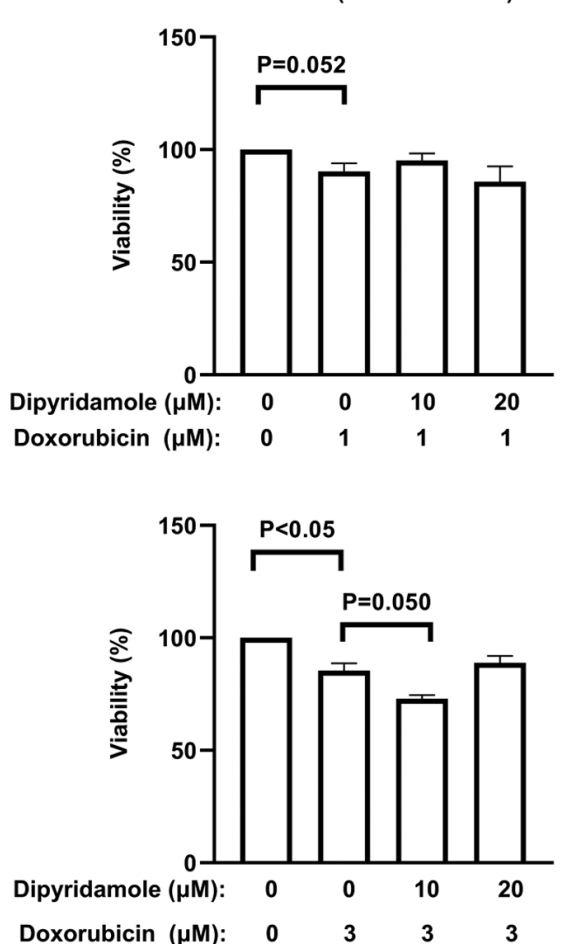

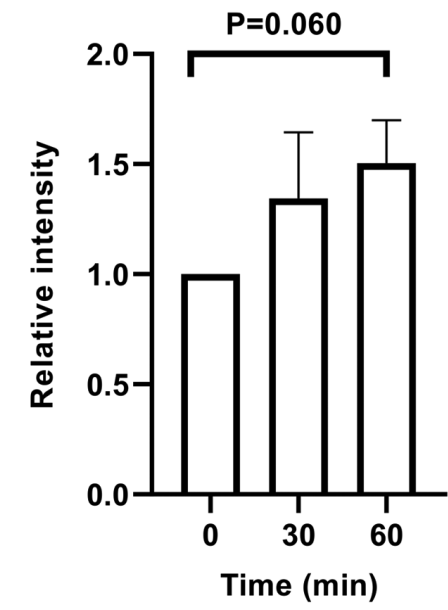

C

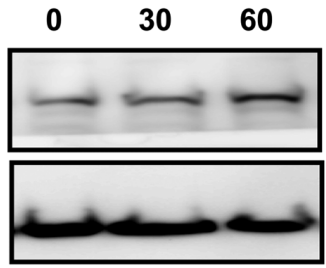




\section{Acknowledgements}

Not applicable.

\section{Funding}

The present study was supported by the Egyptian ministry of Higher Education (grant no. CAM-751-FM-06-01).

\section{Availability of data and materials}

All data generated or analyzed during this study are included in this published article.

\section{Authors' contributions}

LA performed the experiments, acquired, analyzed and interpreted the data, and drafted the manuscript. NEM designed the current study and gave final approval for the manuscript to be published. TK and SG performed the experiments. TSL conceived the current study, performed the experiments and wrote and reviewed the final manuscript. TSL also gave final approval for the manuscript to be published and supervised the study. All authors read and approved the final manuscript.

\section{Ethics approval and consent to participate}

Not applicable.

\section{Patient consent for publication}

Not applicable.

\section{Competing interests}

The authors declare that they have no competing interests.

\section{References}

1. Gresele P, Momi S and Falcinelli E: Anti-platelet therapy: Phosphodiesterase inhibitors. Br J Clin Pharmacol 72: 634-646, 2011

2. Thomé MP, Pereira LC, Onzi GR, Rohden F, Ilha M, Guma FT, Wink MR and Lenz G: Dipyridamole impairs autophagic flux and exerts antiproliferative activity on prostate cancer cells. Exp Cell Res 382: 111456, 2019.

3. Kohnoe S, Maehara Y, Takahashi I, Emi Y, Baba H and Sugimachi K: Treatment of advanced gastric cancer with 5-fluorouracil and cisplatin in combination with dipyridamole. Int J Oncol 13: 1203-1206, 1998.

4. Rodrigues M, Barbosa F Jr and Perussi JR: Dipyridamole increases the cytotoxicity of cisplatin in human larynx cancer cells in vitro. Braz J Med Biol Res 37: 591-599, 2004.

5. Kennedy DG, Van den Berg HW, Clarke R and Murphy RF: Enhancement of methotrexate cytotoxicity towards the MDA.MB.436 human breast cancer cell line by dipyridamole. The role of methotrexate polyglutamates. Biochem Pharmacol 35: 3053-3056, 1986.

6. Van Mouwerik TJ, Pangallo CA, Willson JK and Fischer PH: Augmentation of methotrexate cytotoxicity in human colon cancer cells achieved through inhibition of thymidine salvage by dipyridamole. Biochem Pharmacol 36: 809-814, 1987.

7. Spano D, Marshall JC, Marino N, De Martino D, Romano A, Scoppettuolo MN, Bello AM,Di Dato V, Navas L, De Vita G, et al: Dipyridamole prevents triple-negative breast-cancer progression. Clin Exp Metastasis 30: 47-68, 2013.

8. Ge SM, Zhan DL, Zhang SH, Song LQ and Han WW: Reverse screening approach to identify potential anti-cancer targets of dipyridamole. Am J Transl Res 8: 5187-5198, 2016.
9. Sakamoto KM and Frank DA: CREB in the pathophysiology of cancer: Implications for targeting transcription factors for cancer therapy. Clin Cancer Res 15: 2583-2587, 2009.

10. Crans HN and Sakamoto KM: Transcription factors and translocations in lymphoid and myeloid leukemia. Leukemia 15: 313-331, 2001.

11. Seo H, Liu DD, Bekele BN, Kim MK, Pisters K, Lippman SM, Wistuba II and Koo JS: CREB Overexpression: A Feature Associated with Negative Prognosis in Never-Smokers with NSCLC. Cancer Res 68: 6065-6073, 2008.

12. Shaywitz AJ and Greenberg ME: CREB: A stimulus-induced transcription factor activated by a diverse array of extracellular signals. Annu Rev Biochem 68: 821-861, 1999.

13. Fajardo AM, Piazza GA and Tinsley HN: The role of cyclic nucleotide signaling pathways in cancer: Targets for prevention and treatment. Cancers (Basel) 6: 436-458, 2014

14. Brunyanszki A, Olah G, Coletta C, Szczesny B and Szabo C: Regulation of mitochondrial poly(ADP-Ribose) polymerase activation by the $\beta$-adrenoceptor/cAMP/protein kinase A axis during oxidative stress. Mol Pharmacol 86: 450-462, 2014.

15. De Vos M, Schreiber V and Dantzer F: The diverse roles and clinical relevance of PARPs in DNA damage repair: Current state of the art. Biochem Pharmacol 84: 137-146, 2012.

16. Addioui A, Belounis A, Cournoyer S, Nyalendo C, Brito RM, Beaunoyer M, Teira P and Sartelet H: Preclinical study of a PARP inhibitor in neuroblastoma. J Clin Oncol 30 (Suppl 15): 9570, 2012.

17. Brenner JC, Feng FY, Han S, Patel S, Goyal SV, Bou-Maroun LM, Liu M, Lonigro R, Prensner JR, Tomlins SA, et al: PARP-1 inhibition as a targeted strategy to treat Ewing's sarcoma. Cancer Res 72: 1608-1613, 2012.

18. Zaremba T, Thomas H, Cole M, Plummer ER and Curtin NJ: Doxorubicin-induced suppression of poly(ADP-ribose) polymerase-1 (PARP-1) activity and expression and its implication for PARP inhibitors in clinical trials. Cancer Chemother Pharmacol 66: 807-812, 2010.

19. Yan C, Luo L, Guo CY, Goto S, Urata Y, Shao JH and Li TS: Doxorubicin-induced mitophagy contributes to drug resistance in cancer stem cells from HCT8 human colorectal cancer cells. Cancer Lett 388: 34-42, 2017.

20. Kibria G, Hatakeyama H, Akiyama K, Hida K and Harashima H: Comparative study of the sensitivities of cancer cells to doxorubicin, and relationships between the effect of the drug-efflux pump P-gp. Biol Pharm Bull 37: 1926-1935, 2014.

21. Yan C, Luo L, Goto S, Urata Y, Guo CY, Doi H, Kitazato K and Li TS: Enhanced autophagy in colorectal cancer stem cells does not contribute to radio-resistance. Oncotarget 7: 45112-45121, 2016.

22. Omori K and Kotera J: Overview of PDEs and their regulation. Circ Res 100: 309-327, 2007.

23. Klijn C, Durinck S, Stawiski EW, Haverty PM, Jiang Z, Liu H, Degenhardt J, Mayba O, Gnad F, Liu J, et al: A comprehensive transcriptional portrait of human cancer cell lines. Nat Biotechnol 33: 306-312, 2015.

24. Wong JC, Bathina M and Fiscus RR: Cyclic GMP/protein kinase $\mathrm{G}$ type-I $\alpha$ (PKG-I $\alpha$ ) signaling pathway promotes CREB phosphorylation and maintains higher c-IAP1, livin, survivin, and Mcl-1 expression and the inhibition of PKG-I $\alpha$ kinase activity synergizes with cisplatin in non-small cell lung cancer cells. J Cell Biochem 113: 3587-3598, 2012.

25. Ragazzi E, Berti E, Chiodo R, Dancona S and Berti T: Dipyridamole as a modulator of multidrug-resistance in tumor-cells in-vitro. Int J Oncol 6: 659-662, 1995.

26. Weinländer G, Kornek G, Raderer M, Hejna M, Tetzner C and Scheithauer W: Treatment of advanced colorectal cancer with doxorubicin combined with two potential multidrug-resistance-reversing agents: High-dose oral tamoxifen and dexverapamil. J Cancer Res Clin Oncol 123: 452-455, 1997.

27. Krishan A, Sridhar KS, Mou C, Stein WD, Lyubimov E, Hu YP and Fernandez H: Synergistic effect of prochlorperazine and dipyridamole on the cellular retention and cytotoxicity of doxorubicin. Clin Cancer Res 6: 1508-1517, 2,000.

28. Wessler JD, Grip LT, Mendell J and Giugliano RP: The P-glycoprotein transport system and cardiovascular drugs. J Am Coll Cardiol 61: 2495-2502, 2013.

29. Nelson JA and Drake S: Potentiation of methotrexate toxicity by dipyridamole. Cancer Res 44: 2493-2496, 1984.

30. Solomon EI, Augustine AJ and Yoon $\mathrm{J}$ : $\mathrm{O}_{2}$ reduction to $\mathrm{H}_{2} \mathrm{O}$ by the multicopper oxidases. Dalton Trans 30: 3921-3932, 2008.

This work is licensed under a Creative Commons Attribution-NonCommercial-NoDerivatives 4.0 International (CC BY-NC-ND 4.0) License. 